\title{
Microalbuminuria in Healthy Adolescents: A Comparative Study at High Altitude and at Sea Level
}

\author{
Abdias Hurtado $^{*}, 1$, Raquel Cancino ${ }^{2}$, Joel Figueroa ${ }^{2}$, Euclides Padilla ${ }^{2}$, Christian Morales ${ }^{2}$, \\ Irma Ortiz ${ }^{2}$, Shailendra Sharma ${ }^{3}$, Richard J. Johnson ${ }^{3}$ and Jackeline Pando ${ }^{4}$ \\ ${ }^{I}$ The Division of Nephrology, Hospital Arzobispo Loayza, Cayetano Heredia University, Lima, Peru \\ ${ }^{2}$ Division of Family Medicine, Hospital Arzobispo Loayza, Cayetano Heredia University, Lima, Peru \\ ${ }^{3}$ The Division of Renal Diseases and Hypertension, University of Colorado, Denver, USA. and ${ }^{4}$ Department of \\ Paediatrics and Child Health, University College Cork, Ireland
}

\begin{abstract}
Background: High altitude is associated with hypobaric hypoxia and increased risk for microalbuminuria in adults. We hypothesized that healthy adolescents at higher altitude might have an increased frequency of microalbuminuria in comparison with a group of adolescents living at sea level.

Methods: We evaluated the presence of microalbuminuria in adolescents at sea level ( $\mathrm{n}=68$, altitude 130 meters) and at high altitude ( $\mathrm{n}=114$, altitude 3200 meters) living in Peru. Each subject was evaluated for body mass index, Blood Pressure, microalbuminuria, proteinuria, hematuria and leukocyturia in a first morning urine sample. Subjects with a positive test for microalbuminuria underwent repeat testing one or two weeks after the initial screening.

Results: Subjects at sea level and high altitude had similar age, weight, height and blood pressure ( $\mathrm{p}=\mathrm{NS}$ ). Microalbuminuria without any other urinary abnormality, was higher in the first screening among adolescents residing at high altitude compared to those living at sea level (42 vs 15 , p: 0.0215). In the second screening the results were similar in both groups (31 vs 11, p: 0.0879).

Conclusion: Persistent microalbuminuria was observed in more than one-quarter of adolescents living at high altitude. This study suggests that subtle renal injury may occur early in subjects living at high altitude.
\end{abstract}

Keywords: Adolescents, high altitude, microalbuminuria.

\section{INTRODUCTION}

Microalbuminuria (MA) is commonly measured as a risk factor for kidney disease or endothelial dysfunction in diabetic [1] and hypertensive [2] patients. The prevalence of MA among adult healthy population varies between 6 and $8 \%$ and increases with age [3-5].

Over 140 million people live at high altitude (HA), defined as living at an altitude of $2400 \mathrm{~m}$ or more above sea level. They represent $2 \%$ of the world's population [6]. People who reside at HA are exposed to an environment of chronic hypobaric hypoxia. Recent studies done in adult population residing at HA have shown a higher risk of developing renal disease and MA [7,8], but there is no data in younger population. We therefore hypothesized that adolescents at higher altitude might have increased frequency of MA. To test this hypothesis, we conducted a screening for MA and proteinuria among adolescents residing at high altitude and compared it with a group of adolescents living at sea level (SL).

*Address correspondence to this author at the Division of Nephrology, Hospital Arzobispo Loayza, Cayetano Heredia University, Lima 27, Peru. Tel: 511 2248178; Fax: 511 3309361; E-mail: abdias.hurtado@upch.pe

\section{METHODS}

\section{Materials and Subjects}

This was an observational and cross sectional study done between 2011 and 2012. The subjects were Peruvian adolescent students from the last year of high school. There were two groups. The first group resides at HA - in the rural town of Llamellin-Ancash at 3200 meters above sea level. The second group resides in the town of Tahuantinsuyo Lima, at 130 meters above sea level. In the town of Llamellin there were 870 students and in Tahuantinsuyo there were 940 students. To obtain the sample size we used a $5 \%$ error margin with a $95 \%$ confidence level and a heterogeneity level of $10 \%$. The sample size calculated was 129 students.

Teachers and parents were informed about the study and consent forms were obtained. 114 out of 127 students residing at HA accepted to participate in the study, same as 68 out of 96 students residing at SL.

Inclusion criteria were: adolescent students from Llamellin and Tahuantinsuyo on their last year of high school. Signed inform consent obtained from the parents. Exclusion criteria: Students who did not agree to participate in the study, students who at the time of the screening had 
and acute infectious illness, students with a previously known illness, students on medications.

The protocol was approved by the Bioethics Committee of the "Hospital Nacional Arzobispo Loayza", Lima, Peru in accordance with the Declaration of Helsinki.

\section{Procedures}

Past medical history and current health status was obtained among the students who volunteered for the study, so as to exclude those with a current illness. In those subjects selected, there were the following procedures done: Anthropometric measurements: weight and height were obtained after removing shoes and heavy clothes. BMI was calculated [9]. Blood Pressure (BP) measure: subjects were asked to remain seated and at rest for 15 minutes prior to measuring their BP. Three recordings were taken, with a 3 minute interval between each other [10]. OMRON (Japan) calibrated machines were used. Proteinuria screening: The subjects were asked to collect their first morning urine sample (to eliminate the possibility of orthostatic proteinuria) after adequate hygiene. We used Meditest, Combi $10^{\mathrm{R}}$, SGL, Macherey-Nagel urinary dipsticks to measure proteinuria, hematuria and leukocyturia. Meditest is a semiquantative method. The minimum sensitivity of the test strip is $10 \mathrm{mg}$ protein/dL urine. The color fields correspond to the following ranges of albumin concentrations: negative, 1+: $30,2+: 100$ and $3+: 500 \mathrm{mg} / \mathrm{dL}$. MA: was measured in the same morning urine sample, MA was measured using Micral Test ${ }^{\mathrm{R}}$ Roche. A value greater than $20 \mathrm{mg} / \mathrm{L}$ was considered as positive.
In those students who presented with a positive result, both tests were repeated one or two weeks after the initial screening [11].

\section{Statistical Analysis}

The quantitative variables are expressed as mean and standard deviation and the qualitative variables are expressed as percentages. We used $\mathrm{T}$ students and Chi square to compare continuous and discrete variables respectively. A value of $p<0.05$ was considered as statistically significant. We used SPSS 16 to analyze the data.

\section{RESULTS}

There were 114 adolescents evaluated at $\mathrm{HA}$ and 68 at SL. The age range for both groups was 15-18 years. The demographics in both groups were similar and are shown in Table 1. None of the students were hypertensive or obese.

The results of the urinary screening are shown in Table 2. Leukocyturia and hematuria were similar in both groups and both parameters were significantly decreased in the second evaluation. Proteinuria was similar in both groups in the first screening (13/114 (11.4\%) vs 11/68 (16.1\%) and decreased in the second screening $(5 / 13 v s 6 / 11)$.

MA without any other urinary abnormality was higher in the first screening among the adolescents residing at HA compared to those living at SL (42/114 (36.8\%) vs 15/68 (22\%), p: $0.0215)$. In the second screening, MA decreased and the results were similar in both groups ( $31 / 42$ vs 11/15, p: 0.0879).

Table 1. Demographical characteristics of the High Altitude and the Sea Level groups.

\begin{tabular}{|l|c|c|c|}
\hline & High Altitude Group (n:114) & Sea Level Group (n:68) & p Value \\
\hline \hline Gender: Male/Female & $63 / 51$ & $30 / 38$ & 0.1558 \\
\hline Age ( years) & $16.7 \pm 1.3$ & $16.3 \pm 1.0$ & 0.8185 \\
\hline Weight ( kilograms) & $54.9 \pm 7.2$ & $56.9 \pm 8.7$ & 0.8622 \\
\hline Height (meters) & $1.6 \pm 0.1$ & $1.61 \pm 0.07$ & 0.9435 \\
\hline Body mass index* & $21.4 \pm 2.4$ & $21.9 \pm 2.58$ & 0.8926 \\
\hline Systolic Blood Pressure (mmHg) & $115.7 \pm 10.7$ & $120.9 \pm 11.4$ & 0.7523 \\
\hline Diastolic Blood Pressure (mmHg) & $69.3 \pm 9.3$ & $67.2 \pm 8.3$ & 0.8783 \\
\hline
\end{tabular}

*Kilograms $/$ meters $^{2}$.

Table 2. Urinalysis results of the high altitude and the sea level groups.

\begin{tabular}{|l|c|c|c|}
\hline & High Altitude Group 1 & pcreening (n: 114) & Sea Level Group 1 \\
\hline \hline Leukocyturia: $1^{\text {st }}$ screening & 6 & 5 & 0.7492 \\
\hline Leukocyturia: $2^{\text {nd }}$ screening & 0 & 1 & 0.3736 \\
\hline Hematuria: $1^{\text {st }}$ screening & 15 & 6 & 0.2810 \\
\hline Hematuria: $2^{\text {nd }}$ screening & 4 & 13 & 0.0887 \\
\hline Proteinuria: $1^{\text {st }}$ screening & 13 & 6 & 0.4875 \\
\hline Proteinuria: $2^{\text {nd }}$ screening & 5 & 15 & 0.3714 \\
\hline Microalbuminuria: $1^{\text {st }}$ screening & 42 & 11 & 0.0215 \\
\hline Microalbuminuria: $2^{\text {nd }}$ screening & 31 & 0.0879 \\
\hline
\end{tabular}

Microalbuminuria was defined as a value greater than $20 \mathrm{mg} / \mathrm{L}$ using MicralTestR Roche. 


\section{DISCUSSION}

There are few epidemiological studies evaluating MA among children and most of them have been done in children with diabetes and obesity $[12,13]$.

We hypothesized that adolescents living at high altitude would have a higher prevalence of MA. The primary finding was that there was a higher frequency of MA among adolescents living at HA based on a single screening (36.8 vs 22 percent). In the second screening, $31 / 114$ patients $(27 \%)$ still had microalbuminuria in the HA group compared to $11 / 68(16 \%)$ in the sea level group. While the $p$ value was only 0.08 , it is trending towards significance, and may become significant in a larger sample size. The profile of the adolescents with negative MA on the second screening was similar to those who had persistent MA, with no statistical differences among their age, sex, BMI or blood pressure. It is recognized that a second screening evaluation reduces the presence of a positive result for MA up to $75 \%$ in otherwise healthy children $[14,15]$. One of the reasons for this is that MA is very variable from day to day and shows important intra-individual variability suggesting the need for multiple assessments $[16,17]$.

A population - based epidemiological study of CKD in Tibetan population looked at 1189 Tibetans over 18 years of age who were living at altitudes between 3658 and $4200 \mathrm{~m}$, and found an adjusted prevalence of MA of 16\% [7].

The presence of persistent MA in the high altitude population is interesting as adults show an increasing frequency of MA and hypertension, a syndrome called High Altitude Renal Syndrome [8]. The etiology of this syndrome may reflect hypoxia associated endothelial dysfunction, oxidative stress, effects from elevated uric acid, or relate to the higher frequency of low birth weight. Unfortunately, we were not able to test for these possibilities with this study. Exposure of rats to hypobaric hypoxia can induce subtle renal injury in the kidney, including microvascular disease, glomerular hypertrophy, and mild tubulointerstitial inflammation [18].

MA around the world in a single screen shown that in the United States a prevalence of $10.7 \%$ in boys and $19.1 \%$ in girls between 6 and 19 years [19]. Tsioufis in Greece found a prevalence of 5 to $7 \%$ in boys and 12 to $15 \%$ in girls [20]. A study done among the Pima North American native ethnic population, showed a prevalence of $6 \%$ [14]. In Nigeria, a study done among school children found a prevalence of MA of $33 \%$, the prevalence was higher in female adolescent who were obese, hypertensive and diabetics [21]. Transient MA can be seen in children secondary to physical exertion or to febrile illness $[22,23]$ but these conditions were excluded in our study.

The treatment of MA in adults, includes the treatment of the underlying condition (hypertension, diabetes, obesity) and the use of the renin-angiotensin-aldosterone (RAAS) system blocking agents [24]. A small prospective randomised study among people with altitude polycythemia and proteinuria done in La Paz, Bolivia, showed a significant fall in proteinuria $(\mathrm{p}>0.002)$ in those who received Enalapril for 2 years [25]. The treatment of children with MA who have less co-morbidities, opens the possibility of research looking at the natural history of this condition [26].

Limitations of the study include an uneven sample size, with a two-fold higher number of adolescents at HA compared to those at SL. This might influence the results. On the other hand the ideal way to measure MA is by measuring albumin/creatinine ratio, but this was not done in our study due to technical difficulties with preserving samples at HA. Nevertheless, screening for MA using the micraltest is reliable, detects levels as lows as $20 \mathrm{mg} / \mathrm{l}$, and has a sensitivity of $96.7 \%$ and a specificity of $71 \%$ [27-29].

This study suggests that subtle renal injury may not be uncommon in adolescents in Peru. Disease occurring early may have a role in the development of hypertension or chronic kidney disease as an adult. Given that there are over 140 million people who currently live at high altitude, representing $2 \%$ of the world population (6), we recommend further studies evaluating community - based mass screening to help identify individuals at risk for developing CKD.

\section{CONFLICT OF INTEREST}

The authors confirm that this article content has no conflict of interest.

\section{ACKNOWLEDGEMENTS}

This work was partially supported by a grant from the International Society of Nephrology (ISN) Global Outreach Research \& Prevention Committee".

\section{REFERENCES}

[1] Inzucchi SE, Bergenstal RM, Buse JB, et al. Management of hyperglycemia in type 2 diabetes: a patient-centered approach: position statement of the American Diabetes Association (ADA) and the European Association for the Study of Diabetes (EASD). Diabetes Care 2012; 35(6): 1364-79.

[2] Rabi DM, Daskalopoulou SS, Padwal RS, et al. The 2011 Canadian Hypertension Education Program recommendations for the management of hypertension: blood pressure measurement, diagnosis, assessment of risk, and therapy. Can J Cardiol 2011; 27(4): 415-33. e1-2.

[3] Hillege HL, Janssen WM, Bak AA, et al. Microalbuminuria is common, also in a nondiabetic, nonhypertensive population, and an independent indicator of cardiovascular risk factors and cardiovascular morbidity. J Intern Med 2001; 249(6): 519-26.

[4] Garg AX, Clark WF, Salvadori M, et al. Microalbuminuria three years after recovery from Escherichia coli $\mathrm{O} 157$ hemolytic uremic syndrome due to municipal water contamination. Kidney Int 2005; 67(4): 1476-82.

[5] Atkins RC, Polkinghorne KR, Briganti EM, Shaw JE, Zimmet PZ, Chadban SJ. Prevalence of albuminuria in Australia: the AusDiab Kidney Study. Kidney Int Suppl 2004; (92): S22-4.

[6] Moore LG. Human genetic adaptation to high altitude. High Alt Med Biol 2001; 2: 257-79.

[7] Chen W, Liu Q, Wang H, et al. Prevalence and risk factors of chronic kidney disease: a population study in the Tibetan population. Nephrol Dial Transplant 2011; 26(5): 1592-9.

[8] Hurtado Arestegui AH, Fuquay R, Sirota J, et al. High altitude renal syndrome (HARS). J Am Soc Nephrol 2011; 22(11): 1963-8.

[9] CDC Growth charts. National Center for Health Statistics in collaboration with the National Center for Chronic Disease Prevention and Health Promotion; 2000.

[10] The Fourth report on the diagnosis, evaluation, and treatment of high blood pressure in children and adolescents. National Heart, Lung and Blood Institute. National Institutes of Health; 2004. 
[11] Hogg R, Furth S, Lemley K, et al. National Kidney Foundation's Kidney Disease Outcomes Quality Initiative clinical practice guidelines for chronic kidney disease in children and adolescents: evaluation, classification, and stratification. Pediatrics 2003; 111(6 Pt 1); 1416-21.

[12] Alleyn CR, Volkening LK, Wolfson J, Rodriguez-Ventura A, Wood JR, Laffel LMB. Occurrence of microalbuminuria in young people with Type 1 diabetes: importance of age and diabetes duration. Diabet Med 2010; 27(5): 532-7.

[13] Burgert TS, Dziura J, Yeckel C, et al. Microalbuminuria in pediatric obesity: prevalence and relation to other cardiovascular risk factors. Int J Obes (Lond) 2006; 30(2): 273-80.

[14] Kim NH, Pavkov ME, Knowler WC, et al. Predictive value of albuminuria in American Indian youth with or without type 2 diabetes. Pediatrics 2010; 125(4): e844-51.

[15] Murakami M, Yamamoto H, Ueda Y, Murakami K, Yamauchi K. Urinary screening of elementary and junior high-school children over 13-year period in Tokyo. Pediatr Nephrol 1991; 5: 50-3.

[16] Pugliese G, Solini A, Fondelli C, et al. Renal Insufficiency And Cardiovascular Events (RIACE) Study Group. Reproducibility of albuminuria in type 2 diabetic subjects. Findings from the Renal Insufficiency And Cardiovascular Events (RIACE) study. Nephrol Dial Transplant 2011;26(12): 3950-4.

[17] Miller WG, Bruns DE, Hortin GL, et al.; National Kidney Disease Education Program-IFCC Working Group on Standardization of Albumin in Urine. Current issues in measurement and reporting of urinary albumin excretion. Clin Chem 2009; 55(1): 24-38.

[18] Mazzali M, Jefferson JA, Ni Z, Vaziri ND, Johnson RJ. Microvascular and tubulointerstitial injury associated with chronic hypoxia-induced hypertension. Kidney Int 2003; 63: 2088-93.

[19] Jones CA, Francis ME, Eberhardt MS, et al. Microalbuminuria in the US population: third national health and nutrition examination survey. Am J Kidney Dis 2002; 39(3): 445-59.

[20] Tsioufis C, Mazaraki A, Dimitriadis K, Stefanidis CJ, Stefanadis C. Microalbuminuria in the paediatric age: current knowledge and emerging questions. Acta Paediatr 2011; 100(9): 1180-4.
[21] Okpere AN, Anochie IC, Eke FU. Prevalence of microalbuminuria among secondary school children. Afr Health Sci 2012; 12(2): 1407.

[22] Bangstad HJ, Dahl-Jørgensen K, Kjaersgaard P, Mevold K, Hanssen KF. Urinary albumin excretion rate and puberty in nondiabetic children and adolescents. Acta Paediatr 1993; 82(10): 85762.

[23] Davies AG, Postlethwaite RJ, Price DA, Burn JL, Houlton CA, Fielding BA. Urinary albumin excretion in school children. Arch Dis Child 1984 ; 59(7): 625-30.

[24] Kuritzky L, Toto R, Van Buren P. Identification and management of albuminuria in the primary care setting. J Clin Hypertens (Greenwich) 2011; 13(6): 438-49.

[25] Plata R, Cornejo A, Arratia C, et al. Commission on Global Advancement of Nephrology (COMGAN), Research Subcommittee of the International Society of Nephrology. Angiotensin-converting-enzyme inhibition therapy in altitude polycythaemia: a prospective randomised trial. Lancet 2002; 359(9307): 663-6.

[26] Rademacher ER, Sinaiko AR. Albuminuria in children. Curr Opin Nephrol Hypertens 2009; 18(3): 246-51.

[27] Mogensen CE, Viberti GC, Peheim E, et al. Multicenter evaluation of the Micral-Test II test strip, an immunologic rapid test for the detection of microalbuminuria. Diabetes Care 1997; 20(11): 16426.

[28] Jensen JE, Nielsen SH, Foged L, Holmegaard SN, Magid E. The MICRAL test for diabetic microalbuminuria: predictive values as a function of prevalence. Scand J Clin Lab Invest 1996; 56(2): 11722.

[29] Minetti EE, Cozzi MG, Granata S, Guidi E. Accuracy of the urinary albumin titrator stick "Micral-Test" in kidney-disease patients. Nephrol Dial Transplant Off Publ Eur Dial Transpl Assoc - Eur Ren Assoc 1997; 12(1): 78-80.

This is an open access article licensed under the terms of the Creative Commons Attribution Non-Commercial License (http://creativecommons.org/licenses/by-nc/3.0/) which permits unrestricted, non-commercial use, distribution and reproduction in any medium, provided the work is properly cited. 